\title{
Modification of Glassy Carbon Electrode by (E)-2-(Mercapto- phenylamino-methylene)-3-oxo-N-p-tolyl-butanamide for the Determination of Ultra - Trace Levels of Palladium by Adsorptive Stripping Voltammetry
}

\author{
Hamed M. Al-Saidi ${ }^{1}$, Ahmed. A. Gahlan ${ }^{2, *}$ and O. A. Farghaly ${ }^{2}$ \\ ${ }^{1}$ Department of Chemistry, University College in Al - Jamoum, Umm Al-Qura University, 21955, \\ Makkah, KSA. \\ ${ }^{2}$ Chemistry Department, Faculty of Science, Al-Azhar University, Assiut branch, 71524, Assiut, \\ Egypt. \\ *E-mail: ah4424493@gmail.com
}

doi: $10.20964 / 2020.03 .102$

Received: 3 November 2019 / Accepted: 23 December 2019 / Published: 10 April 2020

\begin{abstract}
The present work provides a simple, fast, and inexpensive analytical method for determination of trace palladium (II) using adsorptive stripping voltammetry technique and modified glassy carbon electrode (GCE) as a working electrode. (E)-2-(Mercapto-phenylamino-methylene)-3-oxo-N-p-tolyl-butanamide (MPMPB) was adsorbed on the GC surface to increase the method selectivity and sensitivity by the palladium coordination with this ligand. The proposed method provided extremely low detection limit of palladium $\left(0.002 \mathrm{ng} \mathrm{mL}^{-1}\right)$, whereas, the linearity was in the range of $0.02-0.13 \mathrm{ng} \mathrm{mL}^{-1}$. The systematical study of the interferences of some electroactive species was carried out, and the results showed the high selectivity of the method. The concentration of palladium in some real samples was successfully determined, and the results of proposed procedure were compared with the measurements taken from a standard analytical method (ICP - MS).
\end{abstract}

Keywords: Cathodic Adsorptive Stripping Voltammetry, Palladium, Trace analysis, Electroanalysis, Determination.

\section{$\underline{\text { FULL TEXT }}$}

(C) 2020 The Authors. Published by ESG (www.electrochemsci.org). This article is an open access article distributed under the terms and conditions of the Creative Commons Attribution license (http://creativecommons.org/licenses/by/4.0/). 